Seção Temática: Os Recursos Públicos em Disputa

Volume $11-2021 \mid$ n. 21

\title{
Educação Pública para Além do Neoliberalismo: O Projeto de Alternativas (TAP) - Entrevista com Steven Klees
}

\author{
Public Education Beyond Neoliberalism: The Alternatives Project \\ (TAP) - Interview with Steven Klees
}

\author{
Thais Rodrigues Marin \\ Universidade Estadual de Campinas (UNICAMP), Campinas/SP - Brasil
}

Steven J. Klees é uma das mais proeminentes vozes na comunidade acadêmica internacional em defesa de sistemas públicos de educação justos, igualitários, progressistas e não privatizados. Graduado em Matemática e com mestrado e doutorado em Economia pela Universidade de Stanford, lecionou nas universidades norte-americanas de Cornell, Stanford e Florida State e, desde 1999, é professor de Política de Educação Internacional na Universidade de Maryland. No Brasil, foi Professor Visitante da Universidade Federal do Rio Grande do Norte e Pesquisador Fulbright da Universidade Federal da Bahia. Atuou como consultor de governos, agências e organizações não governamentais em projetos de mais de 30 países. Foi Presidente e é Membro Honorário da Comparative \& International Education Society (CIES) e é Membro Fundador da Rede Latino-Americana e Africana de Pesquisadores em Privatização da Educação (ReLAAPPe).

Em seus cerca de 45 anos de trajetória profissional, Klees tem se dedicado à investigação das relações entre a educação - em todos os seus níveis de ensino e âmbitos governamentais - e o desenvolvimento econômico e social. Globalização e neoliberalismo, desigualdades educacional e social, direitos humanos, justiça social e alternativas para a educação e o desenvolvimento têm figurado como alguns de seus interesses de pesquisa, sobre os quais escreveu cinco livros e dezenas de artigos acadêmicos e de opinião. Seu trabalho mais recente é a obra The Conscience of a Progressive (A Consciência de um Progressista), de 2020, que apresenta as visões conservadora e liberal sobre diversas questões sociais atuais, contrapondo essas perspectivas à visão progressista e às soluções alternativas que ela oferece.

Em janeiro de 2021, durante o Fórum Social Mundial, Klees e um grupo de acadêmicos, líderes sindicais, movimentos sociais e outros atores da sociedade civil lançaram o The Alternatives Project - TAP (O Projeto de Alternativas) ${ }^{1}$, uma rede global de ativistas que defendem a educação pública justa e igualitária como estratégia fundamental para a transformação social, econômica, política e climática. O grupo pretende mobilizar e dar visibilidade a análises e experiências educacionais alternativas, inscritas na contramão das

Para saber mais sobre O Projeto de Alternativas, acesse: thealternativesproject.org 
Educação Pública para Além do Neoliberalismo: O Projeto de Alternativas (TAP) - Entrevista com Steven Klees

ideias e políticas hegemônicas, pautadas pela lógica do capitalismo neoliberal e por um modelo de educação organizada como um mercado competitivo que cria e reproduz desigualdades.

A ideia inicial do TAP começou a se desenvolver em 2019, durante a $63^{\text {a }}$ Conferência Anual da CIES, com um grupo pioneiro de 21 participantes. Com a formalização do TAP, sua primeira iniciativa foi a elaboração da declaração Justiça da Educação para a Transformação Social: Um Marco para Ação, que estabelece princípios e diretrizes para aqueles que queiram aderir à rede. Disponível em 13 idiomas, o documento já foi assinado por mais de 300 interessados de mais de 50 países. Nesta entrevista, realizada virtualmente em 31 de março de 2021, Klees comenta sobre a criação do TAP e sua atuação na busca pela justiça educacional, em especial sobre as condições de financiamento dos sistemas educacionais para alcançar esse objetivo.

O Projeto de Alternativas, lançado no Fórum Social Mundial de 2021, foi criado por uma rede global de ativistas e pesquisadores para atuar em prol de transformações sociais que contribuam para construir um mundo mais rico, igualitário e sustentável, em especial por meio de pedagogias alternativas e sistemas de educação justos. Qual é a importância de um projeto como esse quando os dados indicam um aumento da concentração da riqueza?

Steven Klees: Nosso mundo está em uma encruzilhada. Enfrentamos crises múltiplas, verdadeiramente existenciais - pobreza e desigualdade que destroem vidas, catástrofe climática e ambiental, racismo e sexismo globais sistêmicos, violência generalizada, guerra e a ameaça de aniquilação nuclear, e a pandemia, que está longe de terminar e tem futuro incerto. Precisamos desesperadamente encontrar maneiras alternativas de viver e de ser, se a humanidade quiser sobreviver e, mais ainda, se quiser prosperar. A educação deve ser vista como parte que integra essas crises e como chave para sua transformação.

Em janeiro de 2021, eu e um grupo global de acadêmicos progressistas, ativistas da sociedade civil e líderes sindicais lançamos O Projeto de Alternativas (TAP) com um webinário no Fórum Social Mundial. Antes do lançamento, passamos algum tempo desenvolvendo uma Declaração de assinatura, um Manifesto, se preferir, situando a educação dentro dessas crises globais e sinalizando a necessidade de transformação da educação e de transformação social. Traduzimos a Declaração para cerca de uma dezena de idiomas (incluindo o português), já temos mais de 300 signatários de todo o mundo e convidamos todos a entrar em nosso site e inserir seu nome.

Embora haja muitos esforços globais progressistas e críticos, que eu saiba (nesta entrevista eu ofereço minha própria visão do TAP, mesmo quando falo sobre "nós"), não há nenhum grupo crítico global ou movimento focado amplamente na transformação da educação e na transformação social. Nossa esperança é que o TAP possa amplificar vozes críticas e se juntar a outras ao redor do mundo. Esperamos contribuir para a transformação da política, das políticas públicas e das práticas por meio do engajamento via webinários, workshops, pesquisas, redes de colaboração e ativismo. 
Educação Pública para Além do Neoliberalismo: O Projeto de Alternativas (TAP) - Entrevista com Steven Klees

Quais são as principais diretrizes, hoje, para a construção da justiça educacional global? Quem se beneficia com a manutenção de desigualdades educacionais?

Steven Klees: O título da Declaração do TAP é Justiça da Educação para a Transformação Social: Um Marco para Ação. A justiça educacional exige, em primeiro lugar, a compreensão de como, muitas vezes, as políticas e práticas educacionais reproduzem uma ordem mundial injusta. As atuais estruturas do sistema mundial tornam muitas questões da sociedade um jogo de soma zero, com vencedores e perdedores a cada partida. As elites em todo o mundo se beneficiam de um sistema educacional que privilegia seus filhos e relega outras crianças à margem.

Para contestar a reprodução, a justiça educacional deve estar conectada à justiça social, climática, econômica e política. Educação para a justiça social significa promover justiça racial, de gênero e para pessoas com deficiência. Educação para a justiça climática significa que ensinamos ecologia humana e não humana e gestão ecológica. Educação para a justiça econômica significa contestar o capitalismo e caminhar em direção a uma economia redistributiva e à democracia no ambiente de trabalho. Educação para a justiça política significa afastar-se do autoritarismo e do nacionalismo xenófobo e avançar em direção à solidariedade global, cooperação e abordagens mais participativas da democracia.

O TAP defende a justiça educacional por meio da garantia pelos governos de educação pública gratuita da primeira infância ao ensino superior e de sistemas de educação públicos totalmente financiados por meio de tributação redistributiva progressiva. Poderia explicar em que consistiria esse modelo tributário? Há anos a Organização das Nações Unidas para a Educação, a Ciência e a Cultura (UNESCO) defende a conversão da dívida externa dos países mais pobres em investimento para o meio ambiente e para a educação. Como você analisa essa proposição? O TAP planeja alguma articulação ou diálogo com governos e agências multilaterais para efeito da implementação de ações como essas?

Steven Klees: Com muita frequência, governos e agências multilaterais têm promovido reformas que pouco ou nada fazem para desafiar a natureza reprodutiva da oferta da educação e de outros serviços sociais. Embora o diálogo possa ser útil, espera-se que o TAP contribua com os movimentos sociais que pressionam governos e agências contestando suas políticas e práticas.

Entre as muitas reformas inevitáveis, mais recursos são necessários para a educação, para outros serviços sociais e para alcançar os Objetivos de Desenvolvimento Sustentável (ODS). A resposta à pandemia em muitos países mostrou que, ao enfrentar uma crise, grandes quantidades de recursos podem ser mobilizadas. Nossas múltiplas crises globais exigem que façamos muito mais do que remendar. Embora a dívida por swaps de ações possa ter lugar, são necessárias mudanças redistributivas mais abrangentes. Todos os países precisam de mais impostos. A ajuda internacional precisa aumentar. O 0,7\% em Assistência Oficial ao Desenvolvimento (AOD), prometido pela comunidade internacional durante décadas, seria um primeiro passo. Precisamos acabar com paraísos fiscais, sonegação e elisão. Precisamos de um imposto global sobre fortunas, como defendido por muitos economistas e outros. Precisamos mudar de um modelo de autointeresse/caridade de ajuda internacional para um modelo no qual as transferências internacionais sejam vistas, naturalmente, como uma 
Educação Pública para Além do Neoliberalismo: O Projeto de Alternativas (TAP) - Entrevista com Steven Klees

questão de justiça, de reparação por décadas, por séculos de colonialismo e neocolonialismo. Compartilhamos um planeta muito ameaçado e injusto. Se sobrevivermos, as gerações futuras olharão para trás e verão os dias de hoje como uma época de barbárie, pouco civilizada. Isso precisa mudar.

\section{Como a comunidade internacional poderia participar e colaborar para a instituição de sistemas públicos gratuitos de educação?}

Steven Klees: O impulso para a privatização da educação, que preocupa muitos de vocês, é reflexo de 40 anos de capitalismo neoliberal. Educação, saúde, água e outros serviços sociais foram transformados em mercadorias. Essa transformação não tem relação com eficácia ou eficiência. Ela é o resultado de duas coisas: ideologia e ganância. A ideologia capitalista geralmente favorece as soluções de mercado e sua versão neoliberal vai além para exaltar o setor privado. A educação é vista como uma potencial fonte de riqueza de $\$ 5$ trilhões e mesmo os mais pobres, os "bilhões de baixo", são vistos como um mercado lucrativo. Que tipo de mundo é este onde cobramos dos mais pobres por serviços básicos? Um mundo capitalista!

A comunidade internacional - ou seja, governos, empresas e agências internacionais - está colaborando, agora, para privatizar ainda mais a educação e outros serviços sociais. Para reverter isso, precisamos de uma mudança radical, uma mudança de paradigma, que reconheça meus pontos anteriores e que reconheça que a responsabilidade pública global pelo planeta e a coleta de recursos necessários por meio de impostos são essenciais para sobreviver e prosperar.

O know-how, a caridade e a responsabilidade social empresariais têm pouco a oferecer. As questões educacionais e de outras políticas públicas, que são complicadas, complexas e democraticamente envolvem múltiplas partes interessadas, são desconhecidas dos líderes empresariais, cujo pensamento hierárquico e simplista, de resultados financeiros, os torna particularmente inadequados para contribuir. A responsabilidade social corporativa nos proporcionou esforços descoordenados, autointeressados, particulares e de pequena escala, que podem ajudar algumas pessoas, mas fazem pouco para resolver os problemas sociais. No Fórum Econômico Mundial de 2019, em Davos, o jornalista e historiador holandês convidado Rutger Bregman disse à elite global para "parar de falar sobre filantropia e começar a falar sobre impostos, impostos, impostos". Esse é o único caminho para termos os sistemas públicos de educação de que o mundo precisa.

Em seu site, o TAP faz referência a uma série de grupos e organizações que vêm desenvolvendo alternativas interessantes em prol da justiça educacional. Poderia comentar sobre alguma dessas alternativas e os impactos positivos que ela tem gerado? Há, entre elas, iniciativas que já são ou poderiam ser aplicadas em escala global?

Steven Klees: O TAP está em sua fase inicial, mas espera estabelecer uma rede com outros grupos que estejam trabalhando na transformação da educação e na transformação social. Um dos grupos mais interessantes que promovem transformação social é o Global Tapestry of Alternatives (Tecido Global de Alternativas, em tradução livre) ${ }^{2}$, que é uma iniciativa "que

2 Para saber mais sobre o Global Tapestry of Alternatives, acesse: globaltapestryofalternatives.org 
Educação Pública para Além do Neoliberalismo: O Projeto de Alternativas (TAP) - Entrevista com Steven Klees

pretende criar redes de solidariedade e alianças estratégicas entre" a grande "variedade de alternativas radicais a este regime dominante, opondo-se a suas raízes capitalistas, patriarcais, racistas, estatistas e antropocêntricas". Recomendo fortemente que vocês conheçam a iniciativa.

Em termos de alternativas na educação, vários organizadores do TAP têm trabalhado com o PEHRC, o Privatisation in Education and Human Rights Consortium (Consórcio Global sobre Privatização da Educação e Direitos Humanos), uma organização com a qual alguns de vocês devem estar familiarizados. Ela tem contribuído para o desenvolvimento e a promoção dos Princípios de Abidjan ${ }^{3}$, que delineiam "as obrigações dos Estados, em termos de direitos humanos, de fornecer educação pública e regular o envolvimento privado na educação". Os Princípios de Abidjan foram aplicados globalmente para contestar a privatização da educação generalizada. O PEHRC está atualmente examinando sistemas de educação pública exemplares, com estudos de caso no Brasil, Cuba, Equador, Índia, Nepal e Vietnã, como parte de seu trabalho de desenvolvimento de contranarrativas à suposta eficácia e eficiência da escola privada. OTAP planeja se conectar mais com estes e outros grupos com ideias semelhantes.

Para O Projeto de Alternativas, a sociedade civil e os movimentos sociais desempenham papel fundamental para construir um mundo mais rico, igualitário e sustentável, não à toa seu lançamento foi no Fórum Social Mundial. Como organizações nacionais ou locais podem colaborar e se envolver com a iniciativa?

Steven Klees: Nós vivemos em um mundo de grandes belezas naturais e de belezas criadas pelos seres humanos. No entanto, muitos são marginalizados e nossa própria existência neste planeta está ameaçada. Estamos em um ponto crítico e realmente precisamos avançar rapidamente. Precisamos de uma mudança radical na política e na economia, uma mudança de paradigma. Movimentos sociais nacionais e globais fortes são fundamentais para impulsionar as transformações necessárias. Esperamos que O Projeto de Alternativas possa contribuir para esses esforços. Acolhemos a colaboração e o envolvimento de indivíduos e organizações do Brasil e de todo o mundo. Se você estiver interessado, por favor, consulte nosso site para saber como entrar em contato conosco. Obrigado por esta oportunidade de compartilhar nosso trabalho!

Thais Rodrigues Marin possui graduação em Comunicação Social pela Universidade Estadual Paulista "Júlio de Mesquita Filho" (Unesp) (2008), mestrado em Ciência Política pela Universidade de São Paulo (USP) (2013) e especialização em Jornalismo Científico pela Universidade Estadual de Campinas (Unicamp) (2016). Atualmente, é doutoranda em Educação da Faculdade de Educação da Unicamp e servidora pública da mesma Universidade.

ORCID: https://orcid.org/0000-0001-9536-5763

E-mail: thais.marin@gmail.com

Recebido em 26 de abril de 2021

Aprovado em 30 de maio de 2021

3 Para saber mais sobre os Princípios de Abidjan, acesse: abidjanprinciples.org 